\title{
Identifiability of vowels and speakers from whispered syllables
}

\author{
VIVIEN C. TARTTER \\ City College of City University of New York, New York, New York
}

\begin{abstract}
In the present experiments, the effect of whisper register on speech perception was measured. We assessed listeners' abilities to identify 10 vowels in [hVd] context pronounced by 3 male and 3 female speakers in normal and whisper registers. Results showed $82 \%$ average identification accuracy in whisper mode, approximately a $10 \%$ falloff in identification accuracy from normally phonated speech. In both modes, significant confusions of [0] for [a] occurred, with some additional significant confusions occurring in whisper mode among vowels adjacent in $F_{1} / F_{2}$ space. We also assessed listeners' abilities to match whispered syllables with normally phonated ones by the same speaker. Each trial contained the matching syllable and two foils whispered by speakers of the same sex as the speaker of the target. Identification performance was significantly better than chance across subjects, speakers, and vowels, with no listener achieving better than $96 \%$ performance. Acoustic analyses measured potential cues to speaker identity independent of register.
\end{abstract}

The understanding of normal speech perception mechanisms has advanced through study of speech perception under degraded listening conditions, such as those resulting from masking noise or filtering (G. A. Miller \& Nicely, 1955), clipping (Licklider \& G. A. Miller, 1951), or minimal synthesis (Cooper, Delattre, Liberman, Borst, \& Gerstman, 1952). Such studies shed light on which properties of the speech signal are critical for phonetic perception and which are resistant to distortion.

Another fruitful approach in speech perception research investigates effects of naturally occurring variability in phonetic productions or perceptions. Such variability arises notably through differences in productions of different speakers (Peterson \& Barney, 1952) and differences in productions of a particular segment in different phonetic environments (Liberman, Cooper, Shankweiler, \& Studdert-Kennedy, 1967). Less studied are utterance-toutterance variations within a speaker and context occurring idiosyncratically or due to age, vocal disguise (Endres, Bambach, \& Flosser, 1971), or changing facial expression (Tartter, 1980). Variability studies also inform as to which properties of the speech signal are critical for phonetic perception. Also, they address issues of perceptual constancy in speech (Shankweiler, Strange, \& Verbrugge, 1977).

Few studies of speech perception have investigated the natural vocal tract produced degradation-whispering. Unlike studies of mechanically or synthetically distorted speech, the study of whispered speech is also interesting

We are grateful to Iris Reyes and Peggy Spier for testing subjects. This research was partially supported by NSF Grant BNS 89-96218, the Children's Hearing Institute of Manhattan Eye, Ear, and Throat Hospital, and PSC CUNY Grant RF669479. Correspondence should be addressed to Vivien C. Tartter, City College, CUNY, Convent Ave. at 138th St., New York, NY 10031. because whispering is a naturally occurring communication mode and a naturally occurring source of withinspeaker variation.

Previous studies of whispered speech perception have largely focused on tonal qualities (Jensen, 1958; Lass, Hughes, Bowyer, Waters, \& Bourne, 1976; Meyer-Eppler, 1957; J. D. Miller, 1961), presumably because of the absence, in whisper register, of periodic pulsing of the vocal folds and thus fundamental frequency $\left(F_{0}\right)$, features believed salient for tone perception. Speakers appear to control "pitch" in whispered sung vowels or intonation contours by producing changes in formant frequencies (Meyer-Eppler, 1957). Correspondingly, listeners match pitch of whispered vowels to whispered second formant $\left(F_{2}\right)$ frequency (Thomas, 1969).

A paralinguistic tonal quality, speaker sex from (whispered) voice has been measured by a number of investigators (Lass et al., 1976; Schwartz \& Rine, 1968; Tartter, 1989). Across studies, identification accuracy is between $75 \%$ and $98 \%$ correct. Kallail and Emanuel reported average formant frequencies for five vowels whispered by 15 male (Kallail \& Emanuel, 1984a) and 20 female (Kallail \& Emanuel, 1984b) subjects. They did not measure sex identifiability, but comparison of their acoustic measurements across studies shows that male formant frequencies were, on average, lower than female formant frequencies. Tartter (1989), likewise, found significantly lower formant frequencies for a male speaker's productions of 18 consonant-vowel (CV) syllables than for a female's.

Studies of word pairs differing phonetically in tone have shown equivocal results. For Norwegian, Swedish, Slovenian, and Mandarin Chinese, Jensen (1958) found an average of $66 \%-81 \%$ correct; however, J. D. Miller (1961) found only $42 \%$ correct with the same procedure for Vietnamese. The difference in results is unexplained. 
Only four studies have investigated perception and/or acoustic characteristics of nontonal segmental distinctions in whispered speech. Danenbring (1980) examined forcedchoice identification of voiced-voiceless cognate $\mathrm{CV}$ pairs for the vowel environments [i, a, u]. The results are difficult to interpret since data are reported as a measure that combines confidence and accuracy. It appears that results were affected by both consonant and vowel values, but that, in some cases, voicing was confidently interpreted in whispered speech. Moreover, good (90\%) identification of voicing and place of articulation in whispered speech was found by Allen and Haggard (1977), incidentally in a dichotic listening study. Their stimuli were limited to bilabial and alveolar stop consonants synthesized to accentuate featural phonetic differences.

In a more comprehensive study of whispered consonant identifiability, Tartter (1989) found an overall accuracy of $64 \%$ for $18 \mathrm{CV}$ syllables, where $\mathrm{V}=$ [a], each whispered naturally by two speakers. Unlike the previously discussed studies, subjects in this experiment were presented with a single syllable on each trial. Each trial provided 18 response alternatives. An analysis of confusions for each phonetic feature showed $72 \%$ accuracy in identifying voicing (.16 bits/stimulus), $91 \%$ accuracy for identifying place of articulation ( 1.06 bits/stimulus), and $86 \%$ accuracy for identifying manner of articulation (1.22 bits/stimulus). In all cases, $\chi^{2}$ values for the confusion tables were significant. Thus, it appears that consonantal information is very well conveyed in whispered speech.

Kallail and Emanuel (1984a, 1984b, 1985) assessed identifiability of five sustained $(3 \mathrm{sec})$ isolated vowels $[i$, a, $u, \Lambda, æ]$, pronounced in normal and whisper registers by a large number of male and female subjects. Listeners identified $65 \%$ of the male speakers' whispered vowels and $80 \%$ of the normally phonated vowels as the targets. Comparable results $(63 \%)$ were obtained for the female speakers' whispered speech (Kallail \& Emanuel, 1984b).

The present study expands investigations of the identifiability of whispered speech. The first experiment derived from the assumption that the results reported by Kallail and Emanuel were a poor estimate of whispered vowel identification. First, vowels are usually more identifiable than are consonants (Licklider \& G. A. Miller, 1951; Studdert-Kennedy \& Shankweiler, 1970); yet, Kallail and Emanuel found the same identification accuracy for vowels as Tartter did for consonants. Second, Kallail and Emanuel used only five vowels, and two of these [i, u] are the most distinctive vowels universally (Lieberman, 1984). In contrast, Tartter (1989) used 18 consonants, unselected for discriminability (e.g., 6 of the consonants were $[b, d, g, p, t$, and $k]$, the least distinctive [see G. A. Miller \& Nicely, 1955], though the most studied, consonants). Third, Kallail and Emanuel maximized signal redundancy by using stimuli sustained for $3 \mathrm{sec}$, rather than the usual syllable rate of about $1 / 4 \mathrm{sec}$. Tartter's CV syllables were produced naturally. Thus, Experiments $1 \mathrm{~A}$ and $1 \mathrm{~B}$ were designed to reassess whispered vowel identification, using a fuller range of English vowels, natural production durations, and a more natural, CVC, context.

Experiment 2 examined speaker identification from whispered speech. As indicated by the foregoing review, a number of investigators have demonstrated the discriminability of speaker sex in whispered speech. We were interested in determining whether vocal qualities differentiating same-sexed speakers were also available in whispered speech and, more precisely, whether a stranger's normally phonated productions can be matched without training or experience to his or her whispered productions. The results of the present experiments indicate that many of the percepts available from normally phonated speech are preserved in whisper mode.

\section{EXPERIMENTS 1A AND 1B}

Kallail and Emanuel (1984a, 1984b, 1985) demonstrated that listeners can identify 3-sec vowel stimuli representing [i, a, $u, \Lambda, æ]$ produced by 15 males and 20 females with $63 \%-65 \%$ accuracy, a $15 \%-20 \%$ drop in identification accuracy for similarly produced normally phonated vowels. Additionally, acoustic measurements indicated higher formant frequencies for whispered vowels than for normally phonated vowels, but that relative formant positions appropriately differentiated the five vowels in whispered speech.

The range of vowels, their production duration, and their production in isolation were unnatural in the present experiments. Experiments $1 \mathrm{~A}$ and $1 \mathrm{~B}$ were designed to rectify these considerations, thereby providing a more valid estimate of the identifiability of whispered vowels. Experiment 1A tested whispered vowel identification after providing familiarization and practice, as was given in the consonant identification task (Tartter, 1989). Experiment $1 \mathrm{~B}$ provided a stronger test of vowel identification, presenting the syllables without familiarization.

\section{Method}

Subjects. Three male and 3 female adult native speakers of English served as speakers. All speakers had been living in the New York metropolitan area for at least 2 years, and all had been educated in the northeastern United States. They appeared to use standard American English dialect.

Twelve native-English speakers served as subjects. They were accepted only if they reported no known hearing loss. The subjects were paid for their participation.

Stimuli and Equipment. Each speaker recorded the syllables [hid, hId, hed, hæd, had, had, hud, had, hUd, had] twice normally phonated and twice whispered. Recordings were made in a quiet room using a directional microphone and Marantz PMD430 cassette tape recorder. Record levels were set separately for normal and whisper modes. One recording of each syllable in each mode was amplified via a Realistic SA-150 integrated amplifier, lowpass filtered at $5 \mathrm{kHz}$ using a Frequency Devices $901 \mathrm{~F}$ filter, digitized at $10 \mathrm{kHz}$ using a Datatranslation 2801A A/D D/A board, and edited into an individual file in a PC-AT clone using Nirvonics 
software. The subjects were tested on-line in an equivalent system, using prescribed protocols derived with Nirvonics software. Stimuli were presented through Yamaha YH-2 headphones attached to a Tascam MH40 headphone amplifier.

Wideband spectrograms (flat shaping, $300-\mathrm{Hz}$ bandwidth, $8-\mathrm{kHz}$ range) were made of the stimuli using a Kay 7800 sonograph.

Procedure. Each subject was tested individually in a soundattenuated chamber. In the first session, the subject was informed that we were interested in measuring how well whispered vowels could be identified and that we would be presenting vowels whispered by different speakers in some sessions and, in other sessions, vowels normally spoken by the same speakers. The experimenter then normally phonated the vowels live voice, face to face, while indicating labels taped over selected keys of the keyboard. The labels signified each vowel: $[\mathrm{i}]=e e,[\mathrm{I}]=\mathrm{i},[æ]=\mathrm{a}$, $[\mathrm{a}]=\mathrm{ah},[\mathrm{J}]=\mathrm{aw},[\mathrm{u}]=\mathrm{u},[\mathrm{\Lambda}]=\mathrm{uh},[\mathrm{r}]=\mathrm{r},[\mathrm{U}]=\infty$, and $[\varepsilon]=$ eh. These were reviewed until the subject was confident of the vowels and their labels. The experimenter then gave a short live-voice test in normal register. Half of the subjects from each experiment then received the whispered vowel test, followed by the normally phonated vowel test. For the other half, test order was reversed.

Six subjects participated in Experiment 1A. For these subjects, each test began with a computer-controlled set of instructions, familiarization, and practice. The instructions repeated those given by the experimenter, explaining that there were 10 different vowels spoken by six different speakers all in the context [hVd]. The subjects were also informed that a response delay or failure of the computer to detect a response (which occurs when a nondesignated key is struck accidentally) would produce a computer reminder and a repeat of the preceding trial at some later point in the experiment. The stimuli (either whisper or normal) were then presented for familiarization. A label appeared on the screen (e.g., "ee"), accompanied by the appropriate stimulus (e.g., [hid]) pronounced by each speaker in the given register. There was a 30-sec break after familiarization, followed by 10 randomly selected practice trials. If the subject had no questions, a block of experimental trials ensued.

Each block of trials contained two repetitions of all stimuli pronounced in the given register, randomized through the block. There were five blocks of trials for each register, with a new familiarization and practice preceding the first block in the new register. The computer issued a new stimulus $2 \mathrm{sec}$ after the subject responded to the preceding stimulus. There was a 30 -sec break after 60 trials. The subjects were given a break between blocks. No subject ran more than three blocks ( 360 trials $\cong 40 \mathrm{~min}$ ) in a single session.

The other 6 subjects participated in Experiment 1B. They began the actual tests immediately following the live-voice instructions. Note that they were given no familiarization with the speakers or actual syllables in the test, but they did receive practice in vowel labeling from the experimenter. This was necessary because English orthography does not uniquely label vowel sounds and naive subjects must be taught phoneme labeling as opposed to spelling. All other procedures were identical for Experiments $1 \mathbf{A}$ and $\mathbf{1 B}$.

\section{Results and Discussion}

Experiment 1A. Responses to each vowel in each mode were tabulated for each subject. Table 1 displays the confusion matrix for responses to normal register collapsed across subjects. The highest possible score is 360: 6 speakers $\times 6$ listeners $\times 10$ trials. A crude approximation for a $95 \%$ confidence interval for chance performance was calculated using the $z$ approximation to the binomial. This yielded a score of 45 for the top of the chance range. The data in Table 1 indicate that above-chance respond- ing occurred for all stimuli in the diagonal, the target responses. The only significant confusion was [0] for [a]. We suspect that this indicates dialect differences between speakers and listeners (or speakers and targets). Peterson and Barney (1952) also found significant confusion between normally phonated [a] and [o].

Table 2 displays a similarly constructed confusion matrix for the whispered syllables. As with the normally spoken tokens, significantly better than chance responses occurred on the diagonal and for [a], of [0]. Significant confusions occurred also of $[\mathrm{U}]$ for whispered $[\Lambda],[I]$ for $[\varepsilon]$, and marginally, [a] for $[0],[\varepsilon]$ for $[I]$, and $[u]$ for [U]. These confusions are between vowels that in normal register typically occupy adjacent regions of the $F_{1} / F_{2}$ vowel space (Peterson \& Barney, 1952).

Table 3 displays the percent correct across speakers for each vowel in each mode. Analyses of variance (register $X$ vowel $X$ subject) performed on the number of correct responses showed that normally phonated vowels were more accurately identified than were whispered vowels $[81.6 \%<92 \%$ correct $; F(1,5)=15.91, p<.025]$. In addition, there were significant differences in identification accuracy across vowels $[F(9,45)=9.44, p<.01]$, and vowel identification accuracy changed significantly with register $[F(9,45)=2.62, p<.05]$. To assess the nature of the vowel effect and the interaction, Fisher's least significant difference statistic (see Winer, 1971) was

Table 1

Confusion Matrix Across Speakers and Subjects for Vowel Identification of Syllables Pronounced in Normal Register

\begin{tabular}{lcccccccccc}
\hline & \multicolumn{10}{c}{ Responses } \\
\cline { 2 - 11 } & $\mathrm{i}$ & $\mathrm{I}$ & $\mathrm{u}$ & $\mathrm{U}$ & $\boldsymbol{\sigma}$ & $\boldsymbol{\varepsilon}$ & $\mathrm{J}$ & $\wedge$ & $\boldsymbol{x}$ & $\mathrm{a}$ \\
\hline $\mathrm{i}$ & 351 & 7 & & 1 & & 1 & & & & \\
$\mathrm{I}$ & & 358 & & & & 2 & & & & \\
$\mathrm{u}$ & & & 352 & 7 & & & & & & 1 \\
$\mathrm{U}$ & & & 9 & 335 & & & & 14 & & 2 \\
$\approx$ & & & 1 & 1 & 356 & 2 & & & & \\
$\varepsilon$ & 1 & & 1 & & 2 & 356 & & & & \\
$\mathrm{o}$ & & & & 1 & & & 320 & 11 & & 28 \\
$\mathrm{\Lambda}$ & & 1 & & 6 & & & 8 & 327 & & 18 \\
$\mathfrak{x}$ & & & & & & 20 & & & 339 & 1 \\
$\mathrm{a}$ & & & & 1 & & 1 & 110 & 29 & & 219 \\
\hline
\end{tabular}

Table 2

Confusion Matrix Across Speakers and Subjects for Vowel Identification of Syllables Pronounced in Whisper Register

\begin{tabular}{lcccccccccc}
\hline & \multicolumn{10}{c}{ Responses } \\
\cline { 2 - 10 } & $\mathrm{i}$ & $\mathrm{I}$ & $\mathrm{u}$ & $\mathrm{U}$ & $\boldsymbol{r}$ & $\boldsymbol{\varepsilon}$ & J & $\wedge$ & $\boldsymbol{x}$ & $\mathrm{a}$ \\
\hline $\mathrm{i}$ & 345 & 9 & & & & 5 & & & 1 & \\
$\mathrm{I}$ & 11 & 303 & & 1 & & 42 & & & 3 & \\
$\mathrm{u}$ & 1 & 3 & 330 & 24 & 1 & & & 1 & & \\
$\mathrm{U}$ & & & 43 & 285 & 1 & & 1 & 29 & 1 & \\
$\mathfrak{x}$ & & & & & 359 & 1 & & & & \\
$\mathrm{c}$ & 2 & 49 & & & & 261 & & & 38 & 10 \\
$\mathrm{~J}$ & & 1 & 9 & 20 & & & 272 & 13 & & 45 \\
$\mathrm{~A}$ & & & 2 & 95 & 1 & & 10 & 228 & & 24 \\
$\mathfrak{x}$ & & 1 & & & & 27 & 1 & & 331 & \\
$\mathrm{a}$ & & & 1 & 11 & & & 96 & 35 & & 217 \\
\hline
\end{tabular}


Table 3

Percent Correct for Each Vowel in Normal and Whisper Registers in Experimental (Experiment 1A) and Control-for-Familiarization (Experiment 1B) Conditions

\begin{tabular}{|c|c|c|c|c|c|c|c|c|c|c|c|}
\hline Register & $\mathrm{i}$ & I & $\mathbf{u}$ & $\mathbf{U}$ & $\alpha$ & $\varepsilon$ & 0 & $\Lambda$ & $\mathfrak{x}$ & $\mathbf{a}$ & $\overline{\bar{X}}$ \\
\hline \multicolumn{12}{|c|}{ Experiment 1A } \\
\hline $\begin{array}{l}\text { Normal } \\
\text { Whisper }\end{array}$ & $\begin{array}{l}97.5 \\
95.8\end{array}$ & $\begin{array}{l}99.4 \\
84.2\end{array}$ & $\begin{array}{l}97.8 \\
91.7\end{array}$ & $\begin{array}{l}93.1 \\
79.2\end{array}$ & $\begin{array}{l}98.9 \\
99.7\end{array}$ & $\begin{array}{l}98.9 \\
72.5\end{array}$ & $\begin{array}{l}88.9 \\
78.3\end{array}$ & $\begin{array}{l}90.8 \\
63.3\end{array}$ & $\begin{array}{l}94.2 \\
91.9\end{array}$ & $\begin{array}{l}60.8 \\
59.7\end{array}$ & $\begin{array}{l}92.0 \\
81.6\end{array}$ \\
\hline \multicolumn{12}{|c|}{ Experiment 1B } \\
\hline $\begin{array}{l}\text { Normal } \\
\text { Whisper }\end{array}$ & $\begin{array}{l}98.9 \\
96.1\end{array}$ & $\begin{array}{l}99.7 \\
85.8\end{array}$ & $\begin{array}{l}97.2 \\
99.4\end{array}$ & $\begin{array}{l}93.1 \\
86.4\end{array}$ & $\begin{array}{l}98.1 \\
99.4\end{array}$ & $\begin{array}{l}99.2 \\
85.3\end{array}$ & $\begin{array}{l}80.1 \\
76.4\end{array}$ & $\begin{array}{l}91.4 \\
74.7\end{array}$ & $\begin{array}{l}88.6 \\
73.6\end{array}$ & $\begin{array}{l}84.7 \\
66.7\end{array}$ & $\begin{array}{l}93.1 \\
84.4\end{array}$ \\
\hline
\end{tabular}

calculated. Overall, [a] was identified significantly worse than were all the other vowels. $[\Lambda]$ and [0] were significantly more poorly recognized than were all but $[\varepsilon]$ and

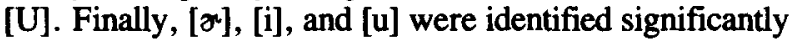
more accurately than were all vowels but $[æ]$ and [I]. The interaction effect proved to be a result of significant decrement from normal to whisper register for all vowels but [æ], [i], [u], [æ], and [a]. Note that four of these vowels relatively unaffected by register change were among the five used by Kallail and Emanuel (1984a, 1984b, 1985).

Experiment 1B. The results of Experiment 1A showed that whispered vowels may be identified at much better than the $65 \%$ accuracy rate found by Kallail and Emanuel (1984a, 1984b, 1985), even with an expanded stimulus and response set and natural duration. One possible explanation that we wished to rule out was that the familiarization and practice procedures, intended to acquaint the subjects with the on-line protocol and task, had actually served as training. Experiment $1 \mathrm{~B}$ was therefore conducted to test this possibility. Here, 6 new subjects were tested without familiarization or practice. Results were analyzed as in Experiment 1A.

Table 3 shows the percent correct for each vowel in each register. Looking at the averages for both experiments, one can see that, in fact, the subjects in this control condition did slightly better than those in the experimental condition; so, if the familiarization acted as training, it certainly was not necessary. As in the experimental condition, the analysis of variance for the control conditions showed a significant main effect of vowel $[F(9,45)=22.95, p<.01]$, register $[F(1,5)=100.41$, $p<.01]$, and their interaction $[F(9,45)=19.85, p<$ .01]. According to the post hoc comparisons, overall, [a] was identified more poorly than was [æ] or [^]. These were identified more poorly than was [U], which was identified worse than was $[\varepsilon]$ or [I]. Finally, [i], [u], and $[\approx]$ were identified better than were all the other vowels. The individual comparisons for the interaction revealed that most whispered vowels were harder to identify than were all normally phonated ones but [i], [ə], and [u]. These vowels were also not adversely affected by whisper register in Experiment 1A. Note that in Experiment 1B, [æ] and [a], when whispered, showed significant decrements that did not appear in Experiment 1A.

The overall pattern of vowel identifiability was similar in the two experiments, the most obvious difference be- ing in the level of [a] identification in normal register. This could represent dialect differences between the two groups of subjects. The general replication of Experiment $1 \mathrm{~A}$ with Experiment $1 \mathrm{~B}$ is also supported by the negative results of a two-way (vowel $\times$ familiarization condition) between-subjects analysis of variance comparing performance in the two whisper conditions. This showed no significant effect of either familiarization $[F(1,100)=1.38$, n.s. $]$ or the interaction $[F(9,100)=$ 1.21 , n.s.].

Generally, then, Experiment 1B replicated Experiment $1 \mathrm{~A}$, allowing the conclusion that the familiarization procedure did not train the subjects to produce better vowel identification overall, and whispered vowel identification in particular. We are tempted to explain at least the differences in identification of [a] in the two conditions to subject dialect differences, since [a] and [0] are highly confusable across dialects of American English (e.g., see Peterson \& Barney, 1952). This may be exacerbated in the identification of whispered vowels of unfamiliar speakers.

The results thus show, as expected, considerably better whispered vowel identification than the $65 \%$ average found by Kallail and Emanuel (1984a, 1984b, 1985) or than the $65 \%$ accuracy found by Tartter (1989) for consonant identification. Note the greater possibility of confusion due to speaker variability in the present experiments than in the consonant study, since here there were 6 speakers rather than 2 . The better vowel identification, relative to consonant identification, presumably results, in part, from the smaller target and response set for vowels (10 as opposed to 18 for consonants). The finding replicates for whisper register the finding of better vowel identification, relative to consonant identification, obtained for normally phonated speech (Licklider \& G. A. Miller, 1951).

The discrepancy between the overall correct found here and in the studies of Kallail and Emanuel may also be due in part to speaker variability, since the earlier research used more than twice as many speakers (15-20) than were used here (6). However, their stimuli were considerably more redundant, sustained for $3 \mathrm{sec}$, and were drawn from a much smaller set of more distinctive vowels. The better results obtained in the present experiments may also derive from the anchor provided by the [hVd] context (Shankweiler, Strange, \& Verbrugge, 1977). 
The consonant context we provided offers another intriguing explanation for the fact that we found greater accuracy of whispered vowel identification than has been previously found (Kallail \& Emanuel, 1984a, 1984b, 1985). There is mounting evidence that vowel identification is enhanced, if not accomplished, through the changing portions of the syllable rather than through steady-state portions; for example, "vowel-less" vowels (syllables with steady states gated out) are reasonably identified (Strange, 1989). It is, therefore, possible that the [hVd] context provided more information as to vowel identity than did the elongated syllables 'of the earlier study.

\section{EXPERIMENT 2}

A number of investigators have explored the identification of speaker sex from whispered speech and shown that it is considerably better than chance (Lass et al., 1976; Schwartz \& Rine, 1968; Tartter, 1989). This is of interest, since $F_{0}$ information, presumably an important differentiator of speaker sex, is absent in whispered speech. Of course, in addition to $F_{0}$, female formant frequencies are higher than male formant frequencies (Peterson \& Barney, 1952). Relative formant positions for different vowels are preserved in whispered speech, although whispered formants tend to be higher than normally phonated ones (Kallail \& Emanuel, 1984a, 1984b). Moreover, pitch in whispered speech is determined from $F_{2}$ frequency (Thomas, 1969). Thus, judges of speaker sex from whispered speech may be making pitch judgments, but ones based on formant rather than $F_{0}$ information. $F_{2}$ frequency differences between the sexes range, on average, from 80 to $250 \mathrm{~Hz}$, or $10 \%-20 \%$ of the formant frequency across vowels (Peterson \& Barney, 1952). Similar differences appear to exist in whispered speech, as can be found in comparisons of the formant measurements in Kallail and Emanuel's (1984a, 1984b) studies.

Sex (and age) accounts for a large difference in speaker voices (Peterson \& Barney, 1952). Thus, a subtle measure of speaker identifiability from whispered speech would test within-speaker (and age) differences rather than sex discriminability. This appears not to have been assessed previously.

In Experiment 2, we undertook such an assessment. The test was relatively rigorous, since the speakers to be identified were not previously known to the subjects and since the "identification" was accomplished by matching a normally phonated syllable to a whispered syllable, with no specific training pairing the normally phonated and whispered stimuli.

\section{Method}

Subjects. The subjects who served in Experiment $1 \mathrm{~A}$ also served in Experiment 2. They were asked to return for this experiment and were paid a bonus for so doing.

Stimuli and Equipment. The stimuli used for Experiment 1 were also used for Experiment 2. The difference was only in terms of composition of stimuli for a trial. In Experiment 2, a normally phonated syllable was presented and, after a 1-sec pause, the same syl- lable whispered by 3 speakers of the same sex as the speaker of the normally phonated one were presented in random order. On one third of the trials, for each syllable and speaker, the whispered syllable spoken by the same person who spoke the normally phonated syllable was first; on another third, it was second; on a final third of the trials, it was spoken third. Syllables, speakers, and position of matching syllable were randomized across blocks of trials. Each block consisted of three trials for each speaker and syllable, or 180 trials all together.

The subjects were tested on line using the same setup as that used in Experiments $1 \mathrm{~A}$ and $1 \mathrm{~B}$.

Procedure. Each subject was familiarized with the speakers' syllables in normal register only. Four practice trials followed. The familiarization consisted of a message (e.g., " $a$ as in had"), followed by the corresponding productions of the 6 speakers. Speaker order was preserved across the 10 familiarization trials. The subjects were informed orally and by computer instruction prior to the familiarization that they would be asked to differentiate the speakers, and, therefore, they presumably attended to voice differences. The subjects had also experienced both normally phonated and whispered syllables by all the speakers in the previous experiments, but without the knowledge that they would be asked later to identify speakers from the whispered tokens.

All subjects were tested on three blocks of trials, or nine trials per syllable type per speaker. Identifiability of each speaker was thus assessed by 90 trials for each speaker. Most subjects ran through two blocks in 1 day and returned another day for the final block.

\section{Results and Discussion}

The number of whispered syllables correctly matched to the normally phonated syllables was calculated for each speaker and listener. Table 4 displays the percent correct for each speaker averaged across listeners. As can be seen in the table, performance was better than chance for all speakers $[t(5)=2.75, p<.05]$. In addition, $z$ approximations to the binomial for each listener and each speaker indicated consistently better than chance $(p<.05)$ performance for 4 listeners identifying all speakers and 1 listener identifying 5 of the 6 speakers; however, 1 listener significantly accurately identified only 1 speaker. The range of performance for different listeners was $39.3 \%$ to $96.3 \%$ across speakers and vowels.

The generally good performance of the listeners on this task and the exceptional performance of some listeners (e.g., 96.3\% correct) suggest that unique speaker characteristics are preserved in whispered speech, and may be recognized without training, from experience with normally phonated speech of the same speaker.

Previous studies of speaker characteristics suggested that speech durations and formant frequencies may be important in characterizing individual voices. In particular,

Table 4

Percent Correct for Each Speaker

\begin{tabular}{lccccccc}
\hline & \multicolumn{4}{c}{ Speakers Identified } \\
\cline { 2 - 4 } \cline { 6 - 8 } & \multicolumn{3}{c}{ Males } & & \multicolumn{3}{c}{ Females } \\
\hline P.T. & R.P. & C.C. & H.G. & S.H. & V.T. \\
\hline \% Correct & 62.5 & 67.8 & 57.7 & 61.7 & 57.8 & 46.2 \\
\hline
\end{tabular}

Note-Each speaker was identified significantly better than chance. Chance $=33.3$. 
Endres et al. (1971) measured $F_{0}$ and center formant frequencies in 6 speakers using different vocal disguises and over 15 years to ascertain stable voice characteristics. $F_{0}$ changed considerably with vocal disguise. (Of course, $\boldsymbol{F}_{\mathbf{0}}$ could not have been a cue to speaker in Experiment 2, since it is absent in whisper register.) Formant frequencies above $F_{3}$ also varied considerably, but the lower formant frequencies were relatively stable for speakers even when attempting to disguise their voices. Endres et al. (1971) speculated that "of special importance" in identifying a speaker were difficult-to-measure "general habitual features such as loudness, richness of the voice, and speech dynamics"' (p. 1847). Of these, only speech dynamics may be easily quantified, in the present study, as syllable duration.

To determine whether duration or formant frequency might have contributed to speaker identification here, spectrograms of the whispered and normally phonated syllables were analyzed for overall syllable duration (time between onset of first and last visible energies) and $F_{2}$ frequency (measured at steady-state center). The second formant frequency was chosen because Peterson (1961) reported $F_{1}$ to be relatively weak in amplitude in whispered speech, and we wished to measure one of the lower three formant frequencies on the basis of the results of Endres et al. (1971).

Figure 1 shows spectrograms of a randomly selected vowel, [hId], spoken normally by the male speakers, above the whispered version from the same speaker. Figure 2 shows a similar display for the female speakers. One can see that C.C.'s syllable duration and initial aspiration greatly exceeded those of the other two male speakers and that his $F_{2}$ frequency was considerably higher. Indeed, because of this initial [h], characteristic of all of C.C.'s recorded [hVd] syllables, his normally phonated spectrograms look roughly similar to the whispered ones. P.T.'s syllable duration was the shortest. For the females, differentiating characteristics are not as obvious, but the subjects were less accurate in distinguishing the females (see Table 4).

To compute the reliability of these observations, individual one-way (speaker) analyses of variance of the whispered syllables were computed for each sex and each acoustic measure. Mean results for each speaker and each measure are displayed in Table 5, along with similar means for the normally phonated condition. For both sexes, the analyses for syllable duration were significant $[F(2,27)=40.66, p<.01$, for female; $F(2,27)=14.41$, $p<.01$, for male]. Fisher's least significant difference statistic indicated that H.G.'s syllable duration was significantly shorter than the other two females' and that C.C.'s syllable duration was significantly longer than the other two males'. The analyses of $F_{2}$ frequency were not significant $[F(2,27)=1.6, p>.05$, for females; $F(2,27)$ $<1$, for males]. Of course, this indicates only that there were no consistent differences across vowels for each speaker. For a particular vowel, $F_{2}$ may have reliably differentiated speakers (e.g., if one speaker used a different dialect).

\section{GENERAL DISCUSSION}

The purpose of speech perception research is to identify, in the acoustic signal, mental processing strategies and cues that give rise to normal speech percepts. The present experiments of whispered speech advance these ends by demonstrating a perceptual constancy across the variation produced by register, by indicating the register-
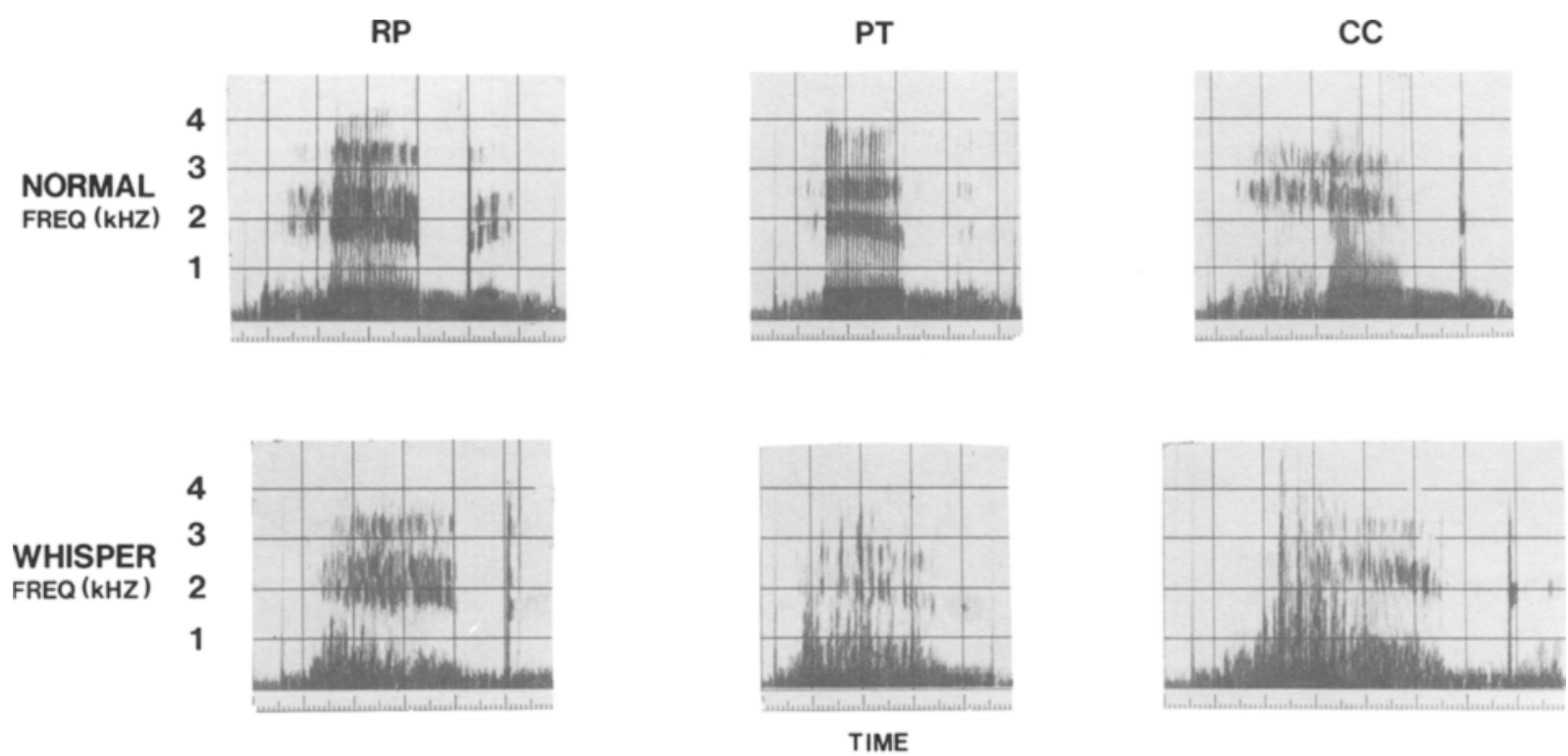

MALES [hld]

Figure 1. Spectrograms of male speakers' normally phonated and whispered syllables [hId]. 

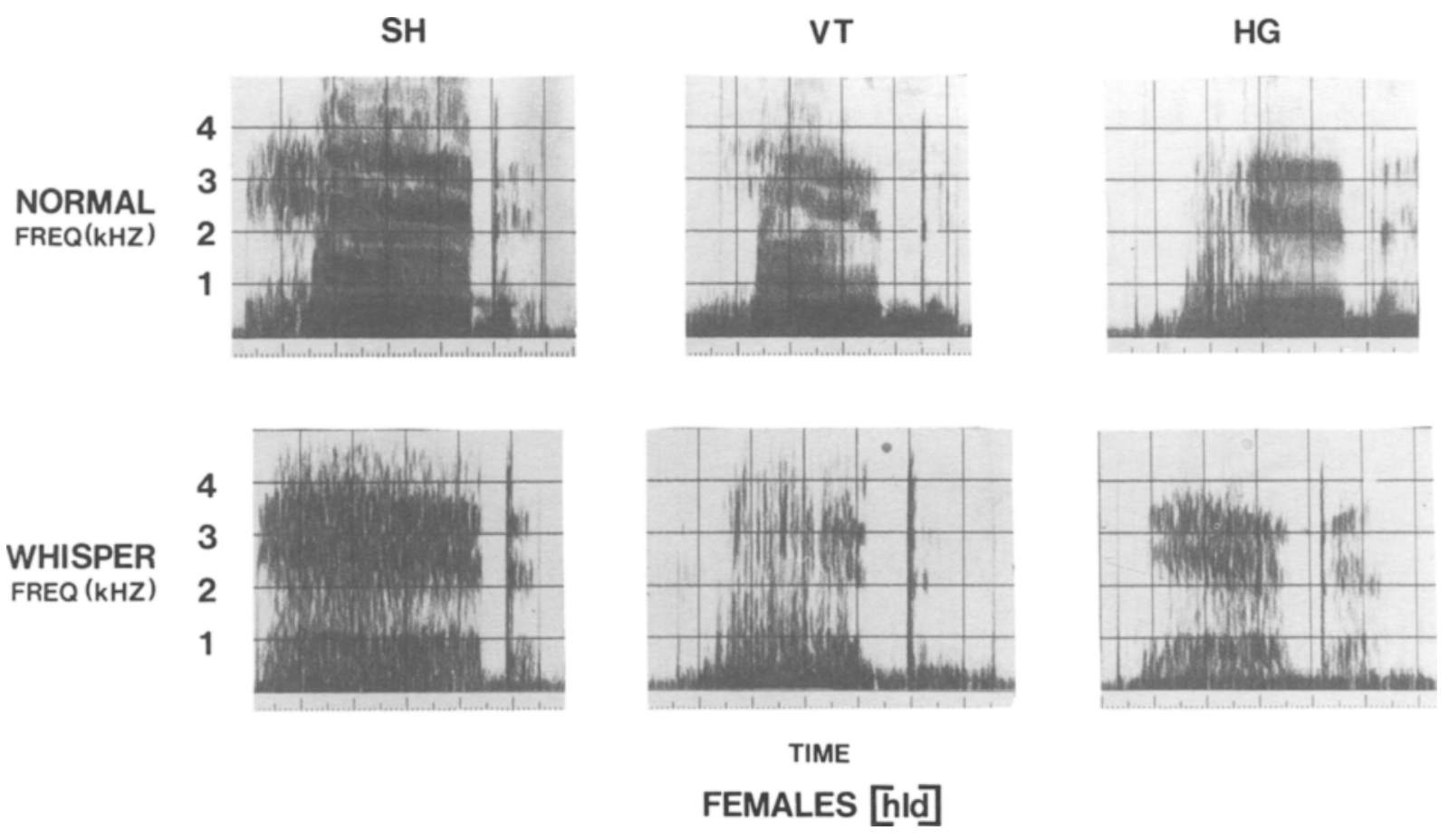

Figure 2. Spectrograms of female speakers' normally phonated and whispered syllables [hId].

independent properties of the articulatory-acoustic signal, and by indicating the efficacy of communication in whisper mode.

In Experiments $1 \mathrm{~A}$ and 1B, we found a better than $80 \%$ absolute identification rate for 10 vowels whispered by 6 different speakers. This represents approximately a $10 \%$ degradation in identifiability of vowels normally phonated by the same speakers, as judged by the same listeners. The overall identification rate found here far exceeds that found by Kallail and Emanuel (1984a, 1984b, 1985). Given that the set of vowels tested here was twice as large as their set, and that the vowels were not unnaturally sustained, it appears that our estimate of whispered vowel identification may be more valid. Compared with Tartter (1989), it also suggests that in whispered speech, vowel identifiability exceeds consonant identifiability, as is true

Table 5

Mean Spectrographic Results for Each Speaker's Normal and Whispered Syllables for Two Acoustic Parameters

\begin{tabular}{lcccccc}
\hline & \multicolumn{3}{c}{ Females } & \multicolumn{3}{c}{ Males } \\
\cline { 2 - 4 } Syllables & V.T. & S.H. & H.G. & P.T. & R.P. & C.C. \\
\hline \multicolumn{5}{c}{ Syllable Duration (msec) } \\
Whispered & 584 & 539 & 482 & 492 & 513 & 654 \\
Normal & 571 & 564 & 491 & 474 & 508 & 580 \\
& \multicolumn{7}{c}{$F_{2}$ Frequency (Hz) } \\
Whispered & 1810 & 1845 & 1890 & 1450 & 1405 & 1695 \\
Normal & 1710 & 1639 & 1610 & 1375 & 1295 & 1510 \\
\hline
\end{tabular}

Note- $F_{2}$ frequency is generally higher for whispered syllables than for normally phonated syllables, an effect previously observed (e.g., Peterson, 1961). for normally phonated speech. Indeed, the whispered vowel identification rate found by Kallail and Emanuel (1984a, 1984b, 1985) for five vowels was only as good as the whispered consonant identification rate found by Tartter (1989) for 18 consonants. This had suggested that their rate was an underestimate.

One possible explanation for the improvement we found in whispered vowel identification accuracy lies in our use of consonant context. Note that vowels produced in isolation consist only of steady states, which were therefore considered to be of vital importance in vowel identification. However, in normal register, the formant transitions provided in CVC syllables have been shown to be very important in vowel identification (Strange, 1989), perhaps because they provide a perceptual anchor or perhaps because of the salience of changing versus steady information. It is interesting that we found whispered vowel identification to be highly accurate in CVC context, whereas Kallail and Emanuel found much lower accuracy with long, steady-state vowels. If this is the reason for the difference between their findings and ours, it adds validity to the observations of Strange (1989) through replication in a different register. Additionally, it suggests that communication in whisper mode uses similar perceptual strategies to communication in normal register.

The present study suggests another similarity between speech perception in normal and whisper registers. The confusions that the subjects made of the whispered vowels were to adjacent vowels in $F_{1} / F_{2}$ space (e.g., [I] for [ $\varepsilon$, or $[\mathrm{u}]$ for $[\mathrm{U}])$. This implies that whispered vowel perception, like normal vowel perception, is based, at least 
in part, on information in the first two formant frequencies. Note that this could not be assumed a priori: (1) Whispered $F_{1}$ has been shown to have a weaker amplitude than does normally phonated $F_{1}$ (Peterson, 1961), and (2) there is no harmonic link between the formants in whisper mode. Studies of sine-wave speech (Remez, Rubin, Pisoni, \& Carrell, 1981), a highly artificial stimulus with no harmonic link between formant frequencies, have proved interesting in part because of the surprising perceptual integration of the nonharmonically related frequencies. Integration produced by a potential single vocal tract configuration, regardless of the resulting harmonic relations, may underlie the intelligibility of both natural whispered speech and the artificial, illusory sinewave speech.

Experiment 2 tested speaker identification from whispered speech. Here, we found significantly better than chance performance in matching whispered syllables to normally phonated ones by the same speaker, despite no direct training in performing such a match. Abilities of listeners to perform the task were quite varied, but the near-perfect performance of one listener suggests that unique speaker characteristics are preserved in whispered speech. Acoustic analyses of the tokens suggest syllable duration as a possible cue to speaker identity, since it consistently differentiated the speakers of the same sex. $F_{2}$ frequency did not consistently differentiate the speakers, but the results do not rule out formant frequency (dialect?) differences between speakers in production of particular vowels, which could have enabled the match between normally phonated and whispered tokens. And, of course, there may be differentiating acoustic cues that we did not analyze in the spectrograms and did not note in introspective listening.

It should be noted that speaker identifiability in whispered speech has not been previously assessed. The better than chance performance across subjects in this task has potential practical significance in criminal cases, for determining reliability of judgments of speaker identity from a whispered excerpt. While not infallible, listeners appear able to match the whispered token to a speaker's voice in the absence of much experience with the speaker whispering. Thus, the results of the present experiments confirm the conclusion of Tartter (1989): There is much in a whisper.

\section{REFERENCES}

Allen, J., \& HaGgard, M. (1977). Perception of voicing and place features in whispered speech: A dichotic choice analysis. Perception \& Psychophysics, 21, 315-322.

Cooper, F. S., Delattre, P. C., Liberman, A. M., Borst, J. M., \& Gerstman, L. J. (1952). Some experiments on the perception of synthetic speech sounds. Journal of the Acoustical Society of America, 24, 597-606.

Dannenbring, G. L. (1980). Perceptual discrimination of whispered phoneme pairs. Perceptual \& Motor Skills, 51, 979-985.
ENDREs, W., BAmbaCh, W., \& Flosser, G. (1971). Voice spectrograms as a function of age, voice disguise, and voice imitation. Journal of the Acoustical Society of America, 49, 1842-1848.

JENSEN, M. K. (1958). Recognition of word tones in whispered speech. Word, 14, 187-196.

Kallail, K. J., \& Emanuel, F. W. (1984a). An acoustic comparison of isolated whispered and phonated vowel samples produced by adult male subjects. Journal of Phonetics, 12, 175-186.

Kallail, K. J., \& EmanUel, F. W. (1984b). Formant-frequency differences between isolated whispered and phonated vowel samples produced by adult female subjects. Journal of Speech \& Hearing Research, 27, 245-251.

Kallail, K. J., Emanuel, F. W. (1985). The identifiability of isolated whispered and phonated vowel samples. Journal of Phonetics, 13, 11-17.

Lass, N. J., Hughes, K. R., Bowyer, M. D., Waters, L. T., \& BourNe, V. T. (1976). Speaker sex identification from voiced, whispered, and filtered isolated vowels. Journal of the Acoustical Society of America, 59, 675-678.

Liberman, A. M., CoOper, F. S., Shankweiler, D. P., \& StuddertKennedy, M. (1967). Perception of the speech code. Psychological Review, 74, 431-461.

Licklider, J. C. R., MiLler, G. A. (1951). The perception of speech. In S. S. Stevens (Ed.), Handbook of experimental psychology (pp. 1040-1074). New York: Wiley.

LiEBerman, P. (1984). The biology and evolution of language. Cambridge, MA: Harvard University Press.

MEYER-EPPLER, W. (1957). Realization of prosodic features in whispered speech. Journal of the Acoustical Society of America, 29, 104-106.

MilLer, G. A., NiCELY, P. E. (1955). An analysis of perceptual confusions among some English consonants. Journal of the Acoustical Society of America, 27, 338-352.

MILLER, J. D. (1961). Word tone recognition in Vietnamese whispered speech. Word, 17, 11-15.

Peterson, G. E. (1961). Parameters of vowel quality. Joumal of Speech \& Hearing Research, 4, 10-29.

Peterson, G. E., Barney, H. L. (1952). Control methods used in the study of vowels. Journal of the Acoustical Society of America, 24, 175-184.

Remez, R. E., Rubin, P. E., Pisoni, D. B., \& Carrell, T. D. (1981). Speech perception without traditional speech cues. Science, 212, 947-950.

SchWARTZ, M. F., \& RINE, H. E. (1968). Identification of speaker sex from isolated, whispered vowels. Journal of the Acoustical Society of America, 44, 1736-1737.

Shankweiler, D., Strange, W., \& Verbrugge, R. (1977). Speech and the problem of perceptual constancy. In R. Shaw \& J. Bransford (Eds.), Perceiving, acting and knowing: Towards an ecological psychology (pp. 315-345). Potomac, MD: Erlbaum.

STRANGE, W. (1989). Evolving theories of vowel perception. Journal of the Acoustical Society of America, 85, 2081-2087.

Studdert-Kennedy, M., \& ShankweILER, D. (1970). Hemispheric specialization for speech perception. Journal of the Acoustical Society of America, 48, 579-594.

TARTTER, V. C. (1980). Happy talk: The perceptual and acoustic effects of smiling on speech. Perception \& Psychophysics, 27, 24-27.

TARTTER, V. C. (1989). What's in a whisper? Journal of the Acoustical Society of America, 86, 1678-1683.

Tномаs, I. B. (1969). Perceived pitch of whispered vowels. Journal of the Acoustical Society of America, 46, 468-470.

WINER, B. J. (1971). Statistical principles in experimental design. New York: McGraw-Hill.

(Manuscript received February 7, 1990; revision accepted for publication December 12, 1990.) 